\title{
Are Underlying Assumptions of Current Animal Models of Human Stroke Correct: from STAIRs to High Hurdles?
}

\author{
Renée J. Turner • Glen C. Jickling • Frank R. Sharp
}

Received: 6 September 2010 /Revised: 18 January 2011 / Accepted: 20 January 2011 /Published online: 12 February 2011

(C) The Author(s) 2011. This article is published with open access at Springerlink.com

\begin{abstract}
Animal models of acute ischemic stroke have been criticized for failing to translate to human stroke. Nevertheless, animal models are necessary to improve our understanding of stroke pathophysiology and to guide the development of new stroke therapies. The rabbit embolic clot model is one animal model that has led to an effective therapy in human acute ischemic stroke, namely tissue plasminogen activator (tPA). We propose that potential compounds that demonstrate efficacy in non-rabbit animal models of acute ischemic stroke should also be tested in the rabbit embolic blood clot model and, where appropriate, compared to tPA prior to investigation in humans. Furthermore, the use of anesthesia needs to be considered as a major confounder in animal models of acute ischemic stroke, and death should be included as an outcome measure in animal stroke studies. These steps, along with the current STAIRs recommendations, may improve the successful translation of experimental therapies to clinical stroke treatments.
\end{abstract}

Keywords Cerebral ischemia - Stroke - Animal models . Neuroprotection $\cdot$ Tissue plasminogen activator $\cdot$ Rabbit

\footnotetext{
R. J. Turner · G. C. Jickling • F. R. Sharp

Department of Neurology, University of California at Davis,

Sacramento, CA 95817, USA

R. J. Turner $\cdot$ G. C. Jickling $\cdot$ F. R. Sharp

M.I.N.D. Institute, University of California at Davis,

Sacramento, CA 95817, USA

R. J. Turner $(\bowtie)$

Discipline of Pathology, The University of Adelaide,

North Terrace,

Adelaide, 5005, SA, Australia

e-mail: renee.turner@adelaide.edu.au
}

\begin{abstract}
Abbreviations
ApoE Apolipoprotein E

FDA Food and Drug Administration

HDL High-density lipoprotein

ICAM-1 Intercellular adhesion molecule 1

LDL Low-density lipoprotein

NXY-059 Free radical scavenger

RSCEM Rabbit small clot embolism model

rt-PA Recombinant tissue plasminogen activator

SAINT I/II Stroke Acute Ischemic Stroke NXY-059 Trial

STAIR Stroke Therapy Academic Industry Roundtable

tPA Tissue plasminogen activator
\end{abstract}

\section{Introduction}

The uncertainty as to why animal studies of acute cerebral ischemia fail to translate into human stroke treatments continues with NXY-059 in the SAINT II trial $[1,2]$. The Stroke Therapy Academic Industry Roundtable (STAIR) recommendations [3-8] have identified important issues in the experimental modeling of ischemic stroke and have sought to promote the translation of animal studies to successful human stroke trials. The STAIR recommendations outline suggestions to optimally pre-clinically assess potential neuroprotective and restorative drugs for the treatment of acute ischemic stroke. Briefly, they include recommendations for drug dose, therapeutic window, choice of animal model, physiological monitoring, outcome measures, and sex differences, amongst others. However, despite such recommendations successful experimental to clinical translation has yet to be achieved. This suggests that further modifications and changes may be required to experimental paradigms in order to achieve such results. 
Rather than assess these criteria, or address the many excellent reviews in the literature [9-12], we instead seek to highlight features of stroke models that may have been underestimated, and some assumptions that have been made in the development of animal models of acute ischemic stroke and the testing of neuroprotective agents. The goal is to promote discussion and possible modification of models to ultimately improve the translation of experimental stroke studies to the clinical setting [9, 10, 13-20].

The inconsistency amongst animal models, in addition to the lack of a clear progression of testing to humans has proved a major obstacle in the translation of treatments from animal models to human stroke. One experimental model which has not been adequately considered in experimental stroke research is the rabbit embolic clot model [21]. To date, this is one of the only models which has yielded/predicted a treatment approved for use in acute ischemic stroke in humans - tissue plasminogen activator (tPA) [22]. Notably, however, tPA was first shown to be efficacious in rodent stroke models [23-30]. Thus, there may be some value in comparing the two models and addressing whether one is "better" than the other particularly since the rabbit model is seldom used. Even though tPA improves outcomes in both the rabbit and rodent models, this does not mean that either model actually would translate to humans. For example, just because hundreds of neuroprotectants work in rodent stroke models, this does not mean they translated to humans. If one assumed, for the sake of argument, that it is the results in the rabbit model that predicted translation to humans, the rabbit model should be used for translational studies. Factors that might account for translation in rabbits and not rodents might include: the rabbit immune system is different from the rodent; the particular blood clot model used; the clotendothelial cell interaction is closer to humans in the rabbit model; rabbit lipid metabolism is closer to humans; the use of death as an outcome measure in the rabbit model; the absence of anesthesia in the rabbit model; and other factors discussed below. Thus, the rabbit results - and possibly not the rodent results - predicted tPA to be a clinical stroke treatment [21, 31-33].

Since it is not possible at present to decide whether the rabbit or the rodent models are "best" for translational studies, we propose that it may be beneficial for compounds that have been found to be effective in non-rabbit models (rat, mouse, non-human primate, and others) to also demonstrate efficacy in the rabbit embolic blood clot model before proceeding to clinical testing. Clearly, it may be useful, more convenient and cost-effective to initially test compounds in rodent blood clot embolic models [34]. Indeed, as highlighted by the STAIR recommendations [3-8], testing potential therapeutics in a second species, and importantly in a species already shown to predict improved outcome in acute ischemic stroke, would improve the likelihood of successful translation. Compounds successful in such a setting should then be given a high priority for evaluation in humans. In contrast, those compounds demonstrating efficacy in only one animal model or species are less likely to be successfully translated into human stroke. We propose that compounds that prove effective in a given model also be tested in the rabbit blood clot embolic model.

This concept also extends to neuroprotection and combination therapy with tPA. Accordingly, when compounds are tested in the rabbit embolic model, they could be evaluated on their own compared to vehicle, but more importantly, where appropriate, they should be compared directly to tPA. A compound shown to improve acute ischemic stroke outcomes comparable to tPA may be more likely to translate to human stroke. This concept would apply to all compounds proposed to improve acute ischemic stroke, including new thrombolytiics and neuroprotectants. That is, if the neuroprotection provided by a "neuroprotectant" is similar to or better than that obtained with tPA, then the "neuroprotectant" is more likely to translate to human stroke. A second consideration is the combination of compounds with tPA. Several neuroprotectants when co-administered with tPA have been identified to improve outcomes in non-rabbit models of acute ischemic stroke [35]. Evaluating such agents further in conjunction with tPA in the rabbit embolic model would provide additional support for potential clinical efficacy.

\section{Acute Ischemic Stroke Models in the Rat and Mouse are not Equivalent to the Rabbit}

Certainly, the rabbit model of ischemic stroke has been used to a lesser extent than rodent models. This may be in part due to the increased cost associated with rabbit experiments. Nevertheless, the predictive power of these animal models may differ considerably. Although tPA improves outcomes in both rat and mice blood clot embolic models [25, 36-38], as well as in the rabbit embolic clot model [21], it does not necessarily follow that since tPA works in both rodents and rabbits that the predictive power of the rabbit model is shared by that of the rodent model. Ideally, one should show efficacy in the rodent and the rabbit clot embolic models. Thus, the rabbit becomes the confirmatory "second animal model" as suggested by the STAIRS recommendations.

Human stroke generally involves progression of underlying vascular disease, and is associated with increasing age, hypertension, diabetes, hyperlipidemia, smoking, and heart disease $[39,40]$. Accordingly, models that incorporate such factors are more likely to be predictive of clinical efficacy than those that do not. None of the animal models 
truly replicate human stroke. They are simply models of stroke. However, choosing the most appropriate animal models for the research question is essential for the success of both experimental and clinical testing. Accordingly, there may be several explanations for the efficacy of the rabbit model and indeed several advantages of this model.

\section{Atherosclerosis}

Rodents and rabbits differ in the development of atherosclerosis. Rabbits develop atherosclerosis and share many aspects of human lipoprotein metabolism. For example, the composition of lipoproteins, production of Apo $\beta 100$ containing VLDLs by liver, cholesteryl ester transfer activity, and high absorption of dietary cholesterol are similar in humans and rabbits [41, 42]. Transgenic rodents are available which have increased plasma cholesterol and triglycerides as well as low high-density lipoprotein levels [42]. Rabbits, however, rapidly develop atherosclerosis on hypercholesterolemic diets $(0.5-4 \% /$ weight $)$ where dietary cholesterol supplementation leads to the development of fatty streaks [41]. Though rodents may also develop atherosclerosis, they are inherently much more resistant than rabbits [43]. Atherosclerosis may be induced in rodents with dietary and genetic manipulations, such as apolipoprotein E (ApoE; -/-) and low-density lipoprotein (LDL; -/-), although they develop very unstable atherosclerotic lesions [44-46]. Furthermore, the cholesterol metabolism of rodents is more geared towards HDL, rather that LDL, like that in both humans and rabbits [45]. This is of clinical relevance as the expression of ApoE and LDL receptors differs in young adult versus old rats following cerebral ischemia [47]. Atherosclerosis is an important risk factor in patients with ischemia [48]. Therefore, consideration of this pathology in animal stroke models is crucial. The simple fact that rabbits develop atherosclerosis whereas normal rodents do not may make the rabbit a better model in which to test compounds for stroke due to the lipid metabolism and/or endothelial differences in rabbits versus rodents. Rabbits are commonly used for the study of atherosclerosis and for cardiovascular diseases for these very reasons $[49,50]$.

\section{The Immune System}

Another issue that has not been considered in animal models of stroke is whether the immune system of the rodent is appropriate for modeling that of human stroke. The immune system is critical in human stroke [51-53] as exemplified by the enlimomab clinical trial [54] where antiICAM-1 antibody significantly worsened stroke outcome
[55]. The composition and type of immune response are important factors in modeling human stroke remains to be seen [56]. The rodent immune cell composition is remarkably different from that of rabbits and humans. Specifically, rodents have a lymphocyte predominance with a 1:5 ratio of neutrophils to lymphocytes. In contrast, rabbits have a $1: 1$ ratio of neutrophils to lymphocytes, which is similar to the immune system in humans who have a 2:1 ratio of neutrophils to lymphocytes [57, 58]. Rodents and humans also differ significantly in the systemic immune cell gene expression response to ischemic stroke [59-63]. Although, this represents only one aspect of the immune system, it suggests that the way the rodent immune system responds to cerebral ischemia may not reflect that of the human immune response to acute ischemic stroke. It is not known whether the rabbit immune response to cerebral ischemia is similar to humans or not.

\section{Anesthesia}

The majority of patients with ischemic stroke are not anesthetized. The effect of a stroke or response to stroke may differ greatly with anesthesia. Accordingly, anesthesia may markedly confound experimental stroke studies. However, there are animal models of stroke that are able to induce an ischemic stroke in conscious animals [21, 6466]. Such models are likely to model human stroke more closely than those models using anesthesia during the induction of stroke. Specifically, the rabbit blood clot embolism model [21] involves the preparation of animals under anesthesia and then later, the stroke is induced in awake, un-anesthetized animals. Moreover, numerous studies have demonstrated anesthetic agents afford a degree of protection from cerebral ischemia [67-70]. Even light surgical anesthesia may substantially reduce infarct size following stroke [71]. Accordingly, the contribution of anesthesia to the experimental paradigm and potential neuroprotection requires careful consideration, and ideally the confounding effects of anesthesia must be eliminated from animal stroke models.

\section{tPA Effectiveness in Human Stroke Provides Insight into Animal Models}

Thrombolysis with tPA is effective in humans in cardioembolic, large vessel thromboembolic, and small vessel lacunar stroke [22, 72]. This finding has important implications for animal models of stroke and for testing of drugs to treat human stroke. Since cardioembolic stroke is due to embolic blood clot, then animal models of embolic autologous clot likely models this type of stroke. There are 
no accepted animal models that mimic large vessel thromboembolic stroke and small vessel lacunar stroke in humans $[73,74]$. However, since tPA improves outcome in all three human ischemic stroke subtypes, this suggests that all three types of human stroke are caused at least in part by clots that are acted upon by tPA. For cardioembolic strokes, the clots would usually come from the heart. For large vessel strokes the clots would come from the parent vessels likely related to atherosclerosis. For lacunar strokes, clots might form because of abnormalities in the vessel wall or platelet vessel wall interactions. Thus, the blood clot embolic animal models - be they rabbit or rodent - could be viewed as reasonable mimics of human cardioembolic, large vessel and lacunar causes of human stroke. Thus, animal models in which tPA was effective might also be considered as potential models of important aspects of the pathophysiology of these three human stroke subtypes. Addressing treatments for all three causes of human stroke is essential for translation to human stroke trials because few human stroke trials to date, with the exception of cardioembolic stroke, have considered the cause of stroke when choosing subjects to treat.

\section{Outcome Measures in Animal Models-What is the Best One?}

In animal studies, a "neuroprotective" compound is typically compared to a "saline or vehicle control." The common outcome measures are either a statistically significant decrease in infarct volume or an improvement in a given behavior [34]. However, these outcome measures in animals may not translate to improving outcomes in human stroke. Thus, alternate outcomes need to also be considered. The original rabbit clot embolic model used death as an outcome measure. This is in contrast to most other animal stroke models. In fact, most rodent studies discard animals that die from as a result of ischemic stroke [75]. Indeed, survival studies are becoming increasingly important as death is an important outcome measure in human studies and may be one of the reasons that the rabbit embolic clot model was predictive of efficacy in humans. Therefore, the inclusion of survival rates in experimental stroke studies is critical in determining the true efficacy of a potential therapeutic agent as excluding animals that have died from the study significantly skews the results so that findings are biased towards surviving animals $[34,75]$. In the various trials of tPA, the drug decreased morbidity and mortality [76]. Even if one accepted standard behavioral measures short of death, the behaviors in rats, mice, rabbits and even primates that predict clinical efficacy of therapies for stroke in humans are unknown. Additionally, outcome measures are evaluated at short times following ischemia and not at the times used in clinical trials. Thus, if nothing else death provides at least one additional outcome measure. Using death as the outcome measure in the rabbit embolic clot model likely means that other behavioral assays do not have to be performed and there would be no need to find the behaviors that translate to humans. Moreover, since death was the major behavioral outcome used to demonstrate tPA efficacy in the rabbit blood clot embolic stroke model, this same behavioral endpoint may be useful when testing new neuroprotectants and/or thrombolytics in the rabbit embolic clot model and probably should be included in rodent stroke models.

\section{Concluding Remarks}

To date, there has been a lack of translation of stroke treatments from animals to humans. The rabbit blood clot model of embolic stroke, in which tPA improved stroke outcomes, may be a relevant animal model for predicting efficacy of a drug in human stroke. We suggest that blood clot embolic models should be the primary ones evaluated, and head to head comparison with tPA should be performed in the rabbit model and other models. The contribution of the immune system and atherosclerosis must be included in experimental models along with the other STAIR recommendations. Additionally, death needs to be included as an outcome measure. Ultimately, the goal of translational stroke research is to find the simplest yet most predictive animal model of ischemic stroke so that potential treatments can be successfully and rapidly moved to the clinic and improve the care of patients with stroke.

Acknowledgment Sources of Support: National Health and Medical Research Council (RJT Australia, \#519365), Canadian Institutes of Health and Research (GJ, Canada), and NIH NS054652 and NS066845 (FRS).

Open Access This article is distributed under the terms of the Creative Commons Attribution Noncommercial License which permits any noncommercial use, distribution, and reproduction in any medium, provided the original author(s) and source are credited.

\section{References}

1. Diener HC, Lees KR, Lyden P, Grotta J, Davalos A, Davis SM, et al. NXY-059 for the treatment of acute stroke: pooled analysis of the SAINT I and II Trials. Stroke. 2008;39:1751-8.

2. Shuaib A, Lees KR, Lyden P, Grotta J, Davalos A, Davis SM, et al. NXY-059 for the treatment of acute ischemic stroke. N Engl J Med. 2007;357:562-71.

3. Fisher M. Recommendations for advancing development of acute stroke therapies: Stroke Therapy Academic Industry Roundtable 3. Stroke. 2003;34:1539-46. 
4. Fisher M, Albers GW, Donnan GA, Furlan AJ, Grotta JC, Kidwell CS, et al. Enhancing the development and approval of acute stroke therapies: Stroke Therapy Academic Industry Roundtable. Stroke. 2005;36:1808-13.

5. Fisher M, Feuerstein G, Howells DW, Hurn PD, Kent TA, Savitz SI, et al. Update of the stroke therapy academic industry roundtable preclinical recommendations. Stroke. 2009;40:224450 .

6. Fisher M, Hanley DF, Howard G, Jauch EC, Warach S. Recommendations from the STAIR V meeting on acute stroke trials, technology and outcomes. Stroke. 2007;38:245-8.

7. Saver JL, Albers GW, Dunn B, Johnston KC, Fisher M. Stroke Therapy Academic Industry Roundtable (STAIR) recommendations for extended window acute stroke therapy trials. Stroke. 2009;40:2594-600

8. STAIR. Recommendations for clinical trial evaluation of acute stroke therapies. Stroke. 2001;32:1598-606.

9. Dirnagl U. Bench to bedside: the quest for quality in experimental stroke research. J Cereb Blood Flow Metab. 2006;26:1465-78.

10. Endres M, Engelhardt B, Koistinaho J, Lindvall O, Meairs S, Mohr JP, et al. Improving outcome after stroke: overcoming the translational roadblock. Cerebrovasc Dis. 2008;25:268-78.

11. Ginsberg MD, Busto R. Rodent models of cerebral ischemia. Stroke. 1989;20:1627-42.

12. Lang JT, McCullough LD. Pathways to ischemic neuronal cell death: are sex differences relevant? J Transl Med. 2008;6:33.

13. Herson PS, Koerner IP, Hurn PD. Sex, sex steroids, and brain injury. Semin Reprod Med. 2009;27:229-39.

14. Howells DW, Porritt MJ, Rewell SS, O'Collins V, Sena ES, van der Worp HB, et al. Different strokes for different folks: the rich diversity of animal models of focal cerebral ischemia. J Cereb Blood Flow Metab. 2010;30:1412-31.

15. Liu S, Zhen G, Meloni BP, Campbell K, Winn HR. Rodent Stroke Model Guidelines for Preclinical Stroke Trials (1st Edition). J Exp Stroke Transl Med. 2009;2:2-27.

16. Lo EH. Experimental models, neurovascular mechanisms and translational issues in stroke research. Br J Pharmacol. 2008;153 Suppl 1:S396-405.

17. Macleod MR, Fisher M, O'Collins V, Sena ES, Dirnagl U, Bath PM, et al. Reprint: good laboratory practice: preventing introduction of bias at the bench. J Cereb Blood Flow Metab. 2009;29:221-3.

18. Savitz SI. A critical appraisal of the NXY-059 neuroprotection studies for acute stroke: a need for more rigorous testing of neuroprotective agents in animal models of stroke. Exp Neurol. 2007;205:20-5.

19. Sena ES, van der Worp HB, Bath PM, Howells DW, Macleod MR. Publication bias in reports of animal stroke studies leads to major overstatement of efficacy. PLoS Biol. 2010;8:e1000344.

20. Willing AE. Experimental models: help or hindrance. Stroke. 2009;40:S152-4.

21. Zivin JA, Fisher M, DeGirolami U, Hemenway CC, Stashak JA. Tissue plasminogen activator reduces neurological damage after cerebral embolism. Science. 1985;230:1289-92.

22. NINDS. Tissue plasminogen activator for acute ischemic stroke. The National Institute of Neurological Disorders and Stroke rt-PA Stroke Study Group. N Engl J Med. 1995;333:1581-7.

23. Busch E, Kruger K, Allegrini PR, Kerskens CM, Gyngell ML, Hoehn-Berlage M, et al. Reperfusion after thrombolytic therapy of embolic stroke in the rat: magnetic resonance and biochemical imaging. J Cereb Blood Flow Metab. 1998;18:407-18.

24. Jiang Q, Zhang RL, Zhang ZG, Ewing JR, Divine GW, Chopp M. Diffusion-, T2-, and perfusion-weighted nuclear magnetic resonance imaging of middle cerebral artery embolic stroke and recombinant tissue plasminogen activator intervention in the rat. $\mathrm{J}$ Cereb Blood Flow Metab. 1998;18:758-67.
25. Papadopoulos SM, Chandler WF, Salamat MS, Topol EJ, Sackellares JC. Recombinant human tissue-type plasminogen activator therapy in acute thromboembolic stroke. J Neurosurg. 1987;67:394-8.

26. Asahi M, Asahi K, Wang X, Lo EH. Reduction of tissue plasminogen activator-induced hemorrhage and brain injury by free radical spin trapping after embolic focal cerebral ischemia in rats. J Cereb Blood Flow Metab. 2000;20:452-7.

27. Kano T, Harada T, Katayama Y. Attenuation of extravasation of tissue plasminogen activator by the free radical scavenger, edaravone: evaluation in a rat thromboembolic stroke model. Neurol Res. 2005;27:499-502.

28. Kano T, Katayama Y, Tejima E, Lo EH. Hemorrhagic transformation after fibrinolytic therapy with tissue plasminogen activator in a rat thromboembolic model of stroke. Brain Res. $2000 ; 854: 245-8$.

29. Overgaard K, Sereghy T, Pedersen H, Boysen G. Effect of delayed thrombolysis with rt-PA in a rat embolic stroke model. J Cereb Blood Flow Metab. 1994;14:472-7.

30. Zhang L, Zhang ZG, Zhang RL, Lu M, Adams J, Elliott PJ, et al. Postischemic (6-Hour) treatment with recombinant human tissue plasminogen activator and proteasome inhibitor PS-519 reduces infarction in a rat model of embolic focal cerebral ischemia. Stroke. 2001;32:2926-31.

31. Chehrazi BB, Seibert JA, Kissel P, Hein L, Brock JM. Evaluation of recombinant tissue plasminogen activator in embolic stroke. Neurosurgery. 1989;24:355-60.

32. Phillips DA, Davis MA, Fisher M. Selective embolization and clot dissolution with IPA in the internal carotid artery circulation of the rabbit. AJNR Am J Neuroradiol. 1988;9:899-902.

33. Phillips DA, Fisher M, Smith TW, Davis MA. The safety and angiographic efficacy of tissue plasminogen activator in a cerebral embolization model. Ann Neurol. 1988;23:391-4.

34. Sicard KM, Fisher M. Animal models of focal brain ischemia. Exp Transl Stroke Med. 2009;1:7.

35. Savitz SI, Fisher M. Future of neuroprotection for acute stroke: in the aftermath of the SAINT trials. Ann Neurol. 2007;61:396-402.

36. Kudo M, Aoyama A, Ichimori S, Fukunaga N. An animal model of cerebral infarction. Homologous blood clot emboli in rats. Stroke. 1982;13:505-8.

37. Meng W, Wang X, Asahi M, Kano T, Asahi K, Ackerman RH, et al. Effects of tissue type plasminogen activator in embolic versus mechanical models of focal cerebral ischemia in rats. J Cereb Blood Flow Metab. 1999;19:1316-21.

38. Zhang RL, Zhang L, Jiang Q, Zhang ZG, Goussev A, Chopp M. Postischemic intracarotid treatment with TNK-tPA reduces infarct volume and improves neurological deficits in embolic stroke in the unanesthetized rat. Brain Res. 2000;878:64-71.

39. Elkind MS, Sacco RL. Stroke risk factors and stroke prevention. Semin Neurol. 1998;18:429-40.

40. Sacco RL. Newer risk factors for stroke. Neurology. 2001;57: S31-4.

41. Dornas WC, Oliveira TT, Augusto LE, Nagem TJ. Experimental atherosclerosis in rabbits. Arq Bras Cardiol. 2010;95:272-8.

42. Moghadasian MH, Frohlich JJ, McManus BM. Advances in experimental dyslipidemia and atherosclerosis. Lab Invest. 2001;81:1173-83.

43. Yanni AE. The laboratory rabbit: an animal model of atherosclerosis research. Lab Anim. 2004;38:246-56.

44. Daugherty A, Lu H, Howatt DA, Rateri DL. Modes of defining atherosclerosis in mouse models: relative merits and evolving standards. Methods Mol Biol. 2009;573:1-15.

45. Russell JC, Proctor SD. Small animal models of cardiovascular disease: tools for the study of the roles of metabolic syndrome, dyslipidemia, and atherosclerosis. Cardiovasc Pathol. 2006; 15:31830. 
46. Verbeuren TJ. Experimental models of thrombosis and atherosclerosis. Therapie. 2006;61:379-87.

47. Hayashi T, Kamada H, Jin G, Deguchi K, Nagotani S, Sehara Y, et al. Different expression of low density lipoprotein receptor and ApoE between young adult and old rat brains after ischemia. Neurol Res. 2006;28:822-5.

48. Mostaza JM, Martin-Jadraque R, Vicente I, San Martin MA, Lahoz C. Patients at high risk of cerebrovascular disease: the REACH study. Cerebrovasc Dis. 2009;27 Suppl 1:77-81.

49. Qureshi AI, Taylor RA. Research priorities for intracranial atherosclerotic diseases. J Neuroimaging. 2009;19 Suppl 1:39S$42 \mathrm{~S}$.

50. Zhang GY, Chen ZQ, Ling F, Li YJ, Wang Y, Gu BX. Establishment of a novel hemodynamic cerebral ischemia model of atherosclerotic rabbit. Neurol India. 2010;58:191-4.

51. Jordan J, Segura T, Brea D, Galindo MF, Castillo J. Inflammation as therapeutic objective in stroke. Curr Pharm Des. 2008;14:3549-64.

52. Tanasescu R, Nicolau A, Ticmeanu M, Luca D, Caraiola S, Cojocaru IM, et al. An immunological approach to cerebral ischemia (I). Immune cells and adhesion molecules. Rom J Intern Med. 2008;46:3-8.

53. Tuttolomondo A, Di Sciacca R, Di Raimondo D, Renda C, Pinto A, Licata G. Inflammation as a therapeutic target in acute ischemic stroke treatment. Curr Top Med Chem. 2009;9:1240-60.

54. Enlimomab. Use of anti-ICAM-1 therapy in ischemic stroke: results of the Enlimomab Acute Stroke Trial. Neurology. 2001;57:1428-34.

55. Furuya K, Takeda H, Azhar S, McCarron RM, Chen Y, Ruetzler $\mathrm{CA}$, et al. Examination of several potential mechanisms for the negative outcome in a clinical stroke trial of enlimomab, a murine anti-human intercellular adhesion molecule-1 antibody: a bedsideto-bench study. Stroke. 2001;32:2665-74.

56. Shah IM, Macrae IM, Di Napoli M. Neuroinflammation and neuroprotective strategies in acute ischaemic stroke-from bench to bedside. Curr Mol Med. 2009;9:336-54.

57. Fauci AS, Braunwald E, Kasper DL, Hauser SL, Longo DL, Jameson JL, et al. Laboratory Values of Clinical Importance. 2009.

58. Fox JG, Anderson LC, Leow FM, Quimby FW. Laboratory Animal Medicine. Academic Press; 2002.

59. Jickling GC, Xu H, Stamova B, Ander BP, Zhan X, Tian Y, et al. Signatures of cardioembolic and large-vessel ischemic stroke. Ann Neurol. 2010;68:681-92.

60. Moore DF, Li H, Jeffries N, Wright V, Cooper Jr RA, Elkahloun A, et al. Using peripheral blood mononuclear cells to determine a gene expression profile of acute ischemic stroke: a pilot investigation. Circulation. 2005;111:212-21.
61. Stamova B, Xu H, Jickling G, Bushnell C, Tian Y, Ander BP, et al. Gene expression profiling of blood for the prediction of ischemic stroke. Stroke. 2010;41:2171-7.

62. Tang Y, Lu A, Aronow BJ, Sharp FR. Blood genomic responses differ after stroke, seizures, hypoglycemia, and hypoxia: blood genomic fingerprints of disease. Ann Neurol. 2001;50:699-707.

63. Tang Y, Xu H, Du X, Lit L, Walker W, Lu A, et al. Gene expression in blood changes rapidly in neutrophils and monocytes after ischemic stroke in humans: a microarray study. J Cereb Blood Flow Metab. 2006;26:1089-102.

64. Callaway JK, Knight MJ, Watkins DJ, Beart PM, Jarrott B. Delayed treatment with AM-36, a novel neuroprotective agent, reduces neuronal damage after endothelin-1-induced middle cerebral artery occlusion in conscious rats. Stroke. 1999;30:2704-12. discussion 2712.

65. Huang SS, Tsai SK, Chih CL, Chiang LY, Hsieh HM, Teng CM, et al. Neuroprotective effect of hexasulfobutylated C60 on rats subjected to focal cerebral ischemia. Free Radic Biol Med. 2001;30:643-9.

66. Sharkey J, Ritchie IM, Kelly PA. Perivascular microapplication of endothelin-1: a new model of focal cerebral ischaemia in the rat. $\mathrm{J}$ Cereb Blood Flow Metab. 1993;13:865-71.

67. Head BP, Patel P. Anesthetics and brain protection. Curr Opin Anaesthesiol. 2007;20:395-9.

68. Kirsch JR, Traystman RJ, Hurn PD. Anesthetics and cerebroprotection: experimental aspects. Int Anesthesiol Clin. 1996;34:73-93.

69. Koerner IP, Brambrink AM. Brain protection by anesthetic agents. Curr Opin Anaesthesiol. 2006;19:481-6.

70. Wang L, Jing W, Hang YN. Glutamate-induced c-Jun expression in neuronal PC12 cells: the effects of ketamine and propofol. J Neurosurg Anesthesiol. 2008;20:124-30.

71. Gelb AW, Bayona NA, Wilson JX, Cechetto DF. Propofol anesthesia compared to awake reduces infarct size in rats. Anesthesiology. 2002;96:1183-90.

72. Hsia AW, Sachdev HS, Tomlinson J, Hamilton SA, Tong DC. Efficacy of IV tissue plasminogen activator in acute stroke: does stroke subtype really matter? Neurology. 2003;61:71-5.

73. Bailey EL, McCulloch J, Sudlow C, Wardlaw JM. Potential animal models of lacunar stroke: a systematic review. Stroke. 2009;40:e451-8.

74. Hainsworth AH, Markus HS. Do in vivo experimental models reflect human cerebral small vessel disease? A systematic review. J Cereb Blood Flow Metab. 2008;28:1877-91.

75. Lapchak P. Translational stroke research using a rabbit embolic stroke model: a correlative analysis hypothesis for novel therapy development. Transl Stroke Res. 2010;1:96-107.

76. Wardlaw JM, Murray V, Berge E, Del Zoppo GJ. Thrombolysis for acute ischaemic stroke. Cochrane Database Syst Rev 2009: CD000213. 